\author{
Marquette University \\ e-Publications@Marquette
}

$1-1994$

\title{
The Substitutability of Equities and Consumer Durable Goods: A Portfolio-Choice Approach
}

Dale J. Knapp

Marquette University

Farrokh Nourzad

Marquette University, farrokh.nourzad@marquette.edu

Follow this and additional works at: https://epublications.marquette.edu/econ_fac

Part of the Economics Commons

\section{Recommended Citation}

Knapp, Dale J. and Nourzad, Farrokh, "The Substitutability of Equities and Consumer Durable Goods: A Portfolio-Choice Approach" (1994). Economics Faculty Research and Publications. 167.

https://epublications.marquette.edu/econ_fac/167 


\title{
The Substitutability of Equities and Consumer Durable Goods: A Portfolio-Choice Approach*
}

\author{
DALE J. KNAPP \\ FARROKH NOURZAD \\ Marquette University \\ Milwaukee, Wisconsin
}

\section{Introduction}

The stock market crash of October 1987 led many economists to lower their forecast of GNP growth for 1988. The rationale was that the loss of wealth that resulted from the crash would force asset holders to reduce their consumption expenditures. Yet a major slowdown in economic growth was not realized in the months following the crash.

Garner [11] explains this fact in terms of the life-cycle hypothesis of consumption. He argues that the potential adverse effect of stock market losses on planned consumption would be spread out over the entire lifetime of asset holders so that the immediate effect of the crash on the level of economic activity would be insignificant. The existing empirical evidence tends to support this view.

Brayton and Mauskopf [3] find that a one dollar decrease in stock market wealth results in a decrease of only 5 cents in consumption spending. Garner [11] reports that other studies obtain similar results with estimates ranging from three to seven cents. Runkle [22] suggests that the insignificant impact of the stock market crash on the real sector may be a result of investors considering the wealth accumulated early in 1987 as temporary. He suggests that investors' current attitudes about their wealth are generally reflected in their spending on durable goods. According to this argument, if the stock market gains of the early 1987 were perceived to be permanent, the tremendous rise in equity prices would have manifested itself in a significant increase in purchases of durable goods.

Runkle [22] suggests that in order to examine whether the stock market gains of early 1987 were considered temporary, the demand for housing in the post-crash period should be examined. Inherent in Runkle's suggestion is the presumption that common stocks and durable goods in general, and housing in particular, are highly substitutable in investors' asset portfolios. Casual observation tends to support this contention.

Using data from 1987 and 1988, Runkle [22] points out that in the first half of 1987 spending on durable goods was below the level consistent with rising stock prices. Immediately after the crash, spending on durable goods actually increased by over 20 percent. Thus it appears that as stock prices rose, consumption of durable goods declined and as equity prices declined, durable goods consumption increased. This is consistent with the notion that stocks and durable goods

*We wish to thank an anonymous referee of this Journal for constructive suggestions. The usual disclaimer applies. 
may be substitute assets. However, anecdotal evidence can be misleading as it does not take into account the effect of other factors.

While a significant portion of the empirical literature is devoted to estimating the degree of substitutability of alternative assets, the vast majority of the studies are concerned with the relationship between money and various near-monies.' What is lacking is an examination of the degree of substitutability between common stocks and consumer durable goods in a multi-asset portfolio choice framework. ${ }^{2}$ Such an analysis is the objective of the present paper.

Using the analytical approach made famous by Chetty [4] and quarterly data covering the period from 1963.4 through 1991.3, we estimate elasticities of substitution between common stocks and residential housing and between stocks and government bonds, Treasury bills, money, the sum of savings and time deposits, and corporate paper. ${ }^{3}$ We also test whether these elasticities changed following the 1987 stock market crash.

We find that there is virtually no substitutability between stocks and other financial assets. Moreover, we find no evidence that asset holders are willing to substitute between stocks and housing. This last finding contradicts Runkle's suggestion that as stock returns decline, consumers may move into housing, or other durable goods. In fact, it appears that individuals consider equities to be a requirement in their portfolio, and are not willing to use other assets as substitutes. We also find that, with one exception, the stock market crash of 1987 did not have a significant impact on the substitutability between common stocks and the other assets. The only exception is that, following the crash, stocks and Treasury bills actually became complements.

The remainder of the paper is divided into four sections. The next section provides a brief review of the approaches that have been used to measure the substitutability of alternative assets. This is followed by section III where the methodology of our empirical analysis is presented. The data and the estimation results are described in section IV. The paper concludes with section V which summarizes this work and offers some suggestions for further research in this area.

\section{Background}

Two approaches have been used to measure the degree of substitutability of different assets. One approach has been to specify the demand for various assets as a function of the asset's own rate of return and the yields on alternative assets and use it to estimates the (partial) cross-price elasticities. An early study of the substitutability between stocks and other financial assets using this approach is that by Hamburger [12]. Using quarterly data from 1952 to 1960 , he found that fluctuations in the value of stocks completely overshadow the short-run movements of other financial assets. He also found that the dividend yield on stocks is not significant in the household demand function for liquid assets. In a later study, Hamburger [13] found that equities are poor substitutes for the liabilities of financial intermediaries.

A disadvantage of the asset-demand approach is that the resulting cross-elasticity estimates may not be symmetrical. For example, based on the demand for demand deposits, Feige [7] finds

1. Feige and Pearce [8] provide an excellent overview of the early work in this area. See also Moroney and Wilbratte [20]. More recent studies include those by Ewis and Fisher [6], Gauger and Schroeter [10], Huang et al. [15], and Miles $[18,19]$.

2. An exception is the work of Aivazian et al. [1] who estimate own and cross (partial) elasticities between equities and mortgages and other assets.

3. The use of housing as a proxy for durable goods follows Runkle's suggestion. 
that these deposits are either independent or weakly complementary to savings deposits and loans. However, based on the demand for savings deposits and loans, he finds that they are weak substitutes for demand deposits. Feige and Swamy [9] also report this type of asymmetry. Moroney and Wilbratte [20] point out another disadvantages of the asset-demand approach. They argue that because various interest rates, representing the asset's own yield as well as the yield on alternative assets, are highly correlated, the estimates of cross-elasticities obtained from this approach are typically unreliable.

Recently, Aivazian, Callen, Krinsky, and Kwan [1] used portfolio analysis and annual data covering the period 1951-1973 to estimate various elasticities between financial assets held in the household sector. They found that the expected-return elasticities of stocks are independent of all other financial assets in that demand for stocks is not significantly affected by changes in the expected returns on other assets. They also found that the variance elasticities of stocks are dramatically different from all other assets. An increase in the riskiness of stocks leads the household sector to move out of stocks and all other asset classes and into mortgages and long-term government bonds. This suggests that most financial assets are not good substitutes for stocks.

The second approach to measuring the degree of substitutability of alternative assets is based on the methodology first used by Chetty [4]. In this approach one estimates the elasticity of substitution between different assets by estimating parameters of a utility function. This requires maximizing a utility function, defined over a set of different assets, subject to a wealth constraint. Depending on the number of assets considered, the optimization exercise yields one or more estimable equations which can be used to estimate the elasticity of substitution between any pair of assets. An advantage of this approach is that it yields symmetrical substitution elasticities. Another advantage is that, because it avoids the multicollinearity problem that is typically faced in the asset-demand approach, the estimates from Chetty's approach are more efficient.

While the literature on the substitutability of various financial assets has grown considerably, not much has been done concerning the substitutability of financial and tangible assets. An exception is the attempt by McGibany and Nourzad [17]. Using quarterly data covering the period from 1959 to 1981 , they apply Chetty's approach and estimate the elasticity of substitution between real capital and other financial assets. They find that, compared to the other financial assets, government bonds are better substitutes for real capital, albeit the elasticity of substitution between these two assets is well below unity.

McGibany and Nourzad [17] did not include common stocks in their model. Moreover, their measure of tangible assets is real capital defined as equipment plus structures, a production input rather than a real asset held in the household sector. As mentioned earlier, our objective is to examine the extent to which common stocks and consumer durable goods are substitutes in the asset holder's portfolio. For this purpose we use the following analytical framework which is due to Chetty.

\section{The Model}

Consider an individual who faces $n$ alternative assets and selects a portfolio by maximizing his/ her utility subject to a wealth constraint. The combination of assets that the individual chooses, given a specific level of utility and the wealth constraint, is manifested in the shape of his/her indifference curve. It is the degree of curvature of this indifference curve that measures the substitutability of a given pair of assets. The first-order necessary conditions for this utility maximization 
problem provide a set of estimable equations, one for each asset. Once estimated, the results can be used to calculate the elasticity of substitution between any two assets.

We assume the individual has the following generalized constant elasticity of substitution (CES) utility function, ${ }^{4}$

$$
U\left(X_{1}, X_{2}, \ldots, X_{n}\right)=\left(\sum_{i=1}^{n} b_{i} X_{i}^{\rho_{i}}\right)^{1 / \rho}
$$

where $X_{i}$ is the quantity of the $i$ th asset in the next period. The individual faces the following wealth constraint,

$$
C_{0}=\sum_{i=1}^{n}\left[X_{i} /\left(1+r_{i}\right)\right]
$$

where $r_{i}$ is the yield on asset $i$ in the current period, and $C_{0}$ is the individual's total wealth.

Several features of this portfolio choice model must be noted. First, it is based on the assumption that the individual chooses his/her asset portfolio independently of his/her consumptionsaving decision. This is the assumption of homothetic separability of the utility function which is often made in this type of analysis $[1 ; 4 ; 17]$. This assumption allows us to treat the individual's total wealth, $C_{0}$, that is to be allocated to various assets as exogenous. ${ }^{6} \mathrm{~A}$ second feature of the model used here is that it is static. This means that intertemporal substitution among different assets are not taken into account. ${ }^{7}$ Finally, the constrained optimization problem is formulated under conditions of certainty. ${ }^{8.9}$

The individual's problem is to choose quantities of different assets so as to maximize the utility function in equation (1) subject to the constraint in equation (2). The first-order necessary conditions associated with the above constrained optimization problem are

$$
b_{j} X_{j}^{\rho_{j}-1} / \rho\left(\sum_{i=1}^{n} b_{i} X_{i}^{\rho_{i}}\right)^{(1-\rho) / \rho}-\lambda\left(1 /\left(1+r_{j}\right)\right)=0, \quad j=1,2, \ldots, n,
$$

where $\lambda$ is the Lagrange multiplier. Manipulating the first-order conditions so as to eliminate $\lambda$ and then taking log and rearranging terms will yield the following systm of $n$ equations,

4. The use of the CES functional form in this context is quite popular $[2 ; 4 ; 15 ; 16 ; 17 ; 18 ; 19 ; 21]$. Other functional forms that have been used include the generalized Box-Cox form [1], the quisihomothetic translog form [23], and the Fourier flexible form [6].

5. Chetty [4] and McGibany and Nourzad [17] consider both a two-asset case and a multi-asset case. We also estimated a series of two-asset models, each pairing stocks against an alternative asset. The results were generally consistent with those from the multi-asset case reported in the text. Given space limitations and the importance of controlling for other influences, we do not report the two-asset case results. We would be glad to supply these results to interested readers on request.

6. Almost all studies of this type assume some kind of separability. For example, Barnett [2] uses a discounted utility function that is weakly separable in consumption and assets within each period. Poterba and Rotemberg [21] assume additive separability across time. Some have tested separability of the utility function in real and monetary variables. For example, Serletis [23] performs parametric tests on different types of weak separability in consumption goods, leisure and services of various monetary assets using a quasi-homothetic translog utility function. Swofford and Whitney [24; 25] on the other hand, use nonparametric tests of weak separability in consumption, leisure and money.

7. For a dynamic treatment of the portfolio-choice problem see Barnett [2], Huang et al. [15], and Poterba and Rotemberg [21].

8. A potential consequence of not taking account of risk differentials among the various assets is that the estimation results may be biased in favor of riskier assets. This would explain, at least in part, weak or nonexistent substitutability between risky private assets and riskless government bonds. This is not a cause for concern to the extent that yield differentials represent risk differentials.

9. For a stochastic model in which the individual maximizes expected discounted utility of real consumption and monetary assets see Poterba and Rotemberg [21]. 


$$
\begin{aligned}
\ln \left(X_{i}\right)= & 1 /\left(\rho_{i}-1\right) \ln \left(b_{n} \rho_{n} / b_{i} \rho_{i}\right)+1 /\left(\rho_{i}-1\right) \ln \left[\left(1+r_{n}\right) /\left(1+r_{i}\right)\right] \\
& +\left(\rho_{n}-1\right) /\left(\rho_{i}-1\right) \ln X_{n} .
\end{aligned}
$$

The problem of simultaneity is apparent as the equation contains both $X_{i}$ and $X_{n}$. However, if we substitute equation (4) into equation (2), we get an implicit relationship between $r_{i}, C_{0}$, and $X_{n}$. This relationship can be solved for $X_{n}$ and, assuming $\ln X_{n}$ has a valid Taylor series expansion in terms of $\ln r_{i}$ and $\ln C_{0}$, we can write this expansion as,

$$
\ln X_{n}=a_{0}+\sum_{i=1}^{n-1} a_{i} \ln \left[\left(1+r_{n}\right) /\left(1+r_{i}\right)\right]+a_{n} \ln C_{0} .
$$

Note that total wealth, $C_{0}$, which enters the model through the wealth constraint (equation (2)), enters the system through equation (5).

When disturbance terms are added to equations (4) and (5), a system of linear regression equations is obtained whose parameters can be estimated using a simultaneous-equations technique. Chetty [4] and McGibany and Nourzad [17], among others, use two-stage least squares (2SLS). This involves estimating equation (5) in the first stage and using the predicted values of $\ln X_{n}$ in equation (4) as an instrument in the second stage. However, single-equation estimation techniques such as 2 SLS would generate inefficient estimates if the error terms of the $n$ equations of the system are correlated. In order to avoid this possibility, we use a system approach and estimate these equations using three-stage least squares (3SLS). ${ }^{10}$

The estimated parameters from equation (4) are used to calculate the Hicks-Allen [14] elasticity of substitution between the $n$th asset, $X_{n}$, and the $i$ th asset, $X_{i}, i=1,2, \ldots, n-1$,

$$
\sigma_{n, i}=\left[\left(1-\rho_{i}\right)+\left(\rho_{i}-\rho_{n}\right) /\left[1+\left(b_{n} \rho_{n} / b_{i} \rho_{i}\right)\left(X_{n}^{\rho_{n}} / X_{i}^{\rho_{i}}\right)\right]\right]^{-1}
$$

Assets $X_{n}$ and $X_{i}$ are Hicks-Allen substitutes if $\sigma_{n, i}$ is positive and are considered complements if the elasticity is negative.

\section{Results}

Using quarterly data for the 1963.4-1991.3 period, we estimate equations (4) and (5) as a system. ${ }^{11}$ Because we are interested in the substitutability of common stocks and other assets, we designate stocks as the $n$th asset and use it as the instrumental variable as specified by equation (5). We then use the results to calculate the elasticity of substitution between stocks $(S T)$, five other financial assets, and one tangible asset. Our measure of stocks is the total number of shares outstanding on the New York Stock Exchange. The financial assets represent both short- and long-term, as well as risky and riskless assets. They are government bonds $(G B)$ with maturities of ten years or longer, Treasury bills $(T B)$, money $(M 1)$, the sum of savings and time deposits $(T D)$, and corporate paper $(C P)$. Our measure of tangible assets is the existing stock of residential housing, which we use as a proxy for consumer durable goods. This allows us to examine

10. Note that if the cross-equation error covariances are zero, the 2SLS and 3SLS approaches would generate the same results.

11. The data on the outstanding volume of government bonds are from various issues of the Federal Reserve Bulletin and those on shares of stocks are from Survey of Current Business. All other data are from the CITIBASE data tape. 
Runkle's contention that common stocks and housing are substitute assets if stock market gains are perceived to be permanent. ${ }^{12},{ }^{13}$

We use the following yields to represent the rates of return on the above assets. For stocks, we use the Standard and Poor's 500-Stock Composite Index of dividend yield and capital gains. We assume $M I$ has zero yield. For long-term government bonds, we use the composite index of yields on Treasury bonds with maturities of ten years or longer. The average of the three-, six-, and twelve-month Treasury bill rates is used for the yield on Treasury bills. ${ }^{14}$ Because the rate on savings and time deposits is not available for the entire sample period, we use the three month Treasury bill yield as a proxy. For corporate paper we use the corresponding yield.

We measure the rate of return to housing using an approach used by Craine [5] to analyze the impact of population growth on the returns to housing and common stocks. Craine defines the rate of return to housing $(R R H)$ as,

$$
R R H_{t}=\left[R N_{t}+\left(H P_{t+1}-H P_{t}\right)\right] / H P_{t}
$$

where $R N$ is the rental return to housing measured by the rent component of the Consumer Price Index (CPI) normalized by the rent for residences in 1972, and HP is the median housing price published by Commerce Department. All nominal values are converted to real terms using the CPI for quantities and the CPI inflation rate for yields.

Before reporting the estimation results we should point out two aspects of our empirical counterparts of equations (4) and (5). First, in several of the regression equations, the yield variable is lagged. This is done in recognition of the fact that the decisions to move out of one asset and into another may not be made simultaneously for all assets. This is especially the case for the decision to convert into less liquid assets. Following Huang et al. [15], we choose the length of lag based on the periodicty of payment of interest on the asset. Thus we lag the yields on government bonds and bills by two quarters and that on commercial paper by one quarter. These lags also generated the lowest final prediction error (FPE), which also led to the choice of a onequarter lag on the return on housing. The rates of return on the liquid assets, namely money and the sum of savings and time deposits, enter the model contemporaneously. ${ }^{15}$ The second point concerning our regression model is that, in order to avoid the possibility of spurious correlation caused by nonstationary time series, we first difference all variables prior to estimation.

The estimation results and the corresponding partial elasticity of substitution between stocks and each of the other six assets are reported in Table I below. ${ }^{16}$ The results suggest that there is vir-

12. To our knowledge, no quarterly data on stock of housing exist. Thus we construct a housing stock series using the stock of housing in 1960, available from the U.S. Census of Housing, and cumulatively add to it the quarterly flow of housing starts using a depreciation rate of $1.5 \%$ per annum. This rate was chosen based on the fact that the resulting quarterly housing stock series nearly matched the actual values in both 1970 and 1980 for which data on existing stock of housing were available.

13. We considered the possibility that an alternative to purchasing real estate property for investment purposes is to invest in some form of real estate trust. However, we could not find price and quantity data for real estate investment trusts or similar types of investments.

14. Ideally, the yields for the short-term treasury bills and long-term government bonds should be weighted using percentage of the quantity of different maturities as weights. However, the necessary data are not available for the entire sample period and thus a simple average is used.

15. We also estimated a version of the model in which no lags were used. The results, including the substitution elasticities, were not markedly different from those reported here.

16. The elasticities of substitution reported in the last row of Table I are calculated using the parameter estimates associated with each equation regardless of whether or not these estimates are statistically significant. Thus each elasticity 
Table I. 3SLS Estimates of Equation (4), 1963.4-1991.3 ${ }^{\text {a }}$

\begin{tabular}{lcccccc}
\hline & $\ln H S$ & $\ln G B$ & $\ln M 1$ & $\ln T D$ & $\ln C P$ & $\ln T B$ \\
\hline $\ln \left(1+r_{S T} / 1+r_{i}\right)$ & -0.0002 & 0.004 & 0.003 & 0.006 & -0.006 & 0.021 \\
& $(1.110)$ & $(0.56)$ & $(0.44)$ & $(1.83)^{* *}$ & $(0.70)$ & $(1.75)^{* *}$ \\
$\ln S T$ & -0.063 & 0.656 & 0.293 & 0.672 & -1.633 & 4.130 \\
& $(5.03)^{*}$ & $(0.91)$ & $(0.87)$ & $(2.68)^{*}$ & $(2.16)^{*}$ & $(3.81)^{*}$ \\
Constant & 0.006 & -0.002 & -0.005 & -0.009 & 0.057 & -0.084 \\
& $(13.9)^{*}$ & $(0.13)$ & $(0.58)$ & $(1.43)$ & $(3.09)^{*}$ & $(3.21)^{*}$ \\
S.E.E. & 0.001 & 0.039 & 0.028 & 0.018 & 0.049 & 0.066 \\
D.W. & 1.95 & 2.36 & 1.72 & 1.92 & 2.03 & 2.40 \\
$\sigma_{S T, i}$ & 0.0002 & 0.006 & -0.004 & $-0.006^{* *}$ & 0.006 & $-0.022^{* *}$ \\
\hline
\end{tabular}

a. Absolute value of $t$-ratios in parentheses.

$*$ Significant at the $1 \%$ level.

$* *$ Significant at the $10 \%$ level.

Legend

$S T=$ Shares of stocks outstanding on the NYSE

$H S=$ Existing stock of residential housing

$G B=$ Government bonds with maturities of ten years and longer

$M 1=$ Stock of money

$T D=$ Sum of savings and time deposits

$C P=$ Commercial paper

$T B=$ Treasury bills with maturities of one year or less

tually no substitutability between equities and other financial assets. The estimated coefficient of the relative yields variable is statistically significant, at the $10 \%$ level, only for the sum of savings and time deposits and for Treasury bills. However, in both cases the estimated coefficients and thus the corresponding elasticities are extremely small $\left(\sigma_{S, T D}=-0.006\right.$ and $\left.\sigma_{S, T B}=-0.022\right)$. The negative signs of these elasticities suggest complementarity between these two assets and stocks in this sample. More on this below where we discuss the effect of the crash of October 1987. The overall result that common stocks and other financial assets are not good substitutes are generally consistent with the findings of Aivazian, et al. [1] and Hamburger [12; 13].

Turning to the substitutability of stocks and housing, the results suggest that individuals do not consider housing to be an appropriate substitute for stocks, despite the tremendous return to housing during the sample period. This is inconsistent with Runkle's temporary-wealth hypothesis which states that individuals substitute into housing when the return on equities declines as equity prices increase. Because Runkle examined the issue using data for 1987 and 1988 only, it may be argued that the stock market crash of October 1987 constituted a structural change that led to a greater degree of substitutability between stocks and tangible assets following the crash. After all, the 1987 stock market crash was unprecedented in history and the magnitude of this crash may have had an impact on the psyche of investors. It might have also affected asset holders decision regarding purchases of durable goods, specifically housing, and impacted their willingness to substitute between other financial assets.

In order to examine whether there was a significant change in the substitutability of the assets

can only be considered different from zero if the parameter estimate of the ratio of returns that is used to calculate it is statistically significant. 
Table II. 3SLS Estimates of Equation (4) with Controls for the Stock Market Crash of 1987.4, 1963.4-1991.3 a

\begin{tabular}{lcccccc}
\hline & $\ln H S$ & $\ln G B$ & $\ln M 1$ & $\ln T D$ & $\ln C P$ & $\ln T B$ \\
\hline $\ln \left(1+r_{S T} / 1+r_{i}\right)$ & -0.0001 & -0.003 & 0.004 & 0.006 & -0.011 & 0.009 \\
& $(0.53)$ & $(0.35)$ & $(0.47)$ & $(1.51)$ & $(1.13)$ & $(0.54)$ \\
$\ln S T$ & -0.071 & 0.480 & 0.315 & 0.713 & -1.182 & 4.718 \\
& $(4.79)^{*}$ & $(0.69)$ & $(0.91)$ & $(2.69)^{*}$ & $(1.79)^{* *}$ & $(3.84)^{*}$ \\
Intercept Dummy & -0.002 & 0.004 & -0.004 & -0.006 & -0.021 & 0.017 \\
& $(2.76)^{*}$ & $(0.26)$ & $(0.76)$ & $(0.76)$ & $(1.12)$ & $(0.60)$ \\
Slope Dummy & -0.0004 & -0.004 & -0.002 & -0.002 & 0.019 & 0.039 \\
& $(0.85)$ & $(0.23)$ & $(0.10)$ & $(0.24)$ & $(0.94)$ & $(1.16)$ \\
Constant & 0.006 & 0.001 & -0.004 & -0.009 & 0.05 & 0.099 \\
& $(14.47)^{*}$ & $(0.07)$ & $(0.55)$ & $(1.34)$ & $(2.97)^{*}$ & $(3.31)^{*}$ \\
S.E.E. & 0.001 & 0.004 & 0.029 & 0.018 & 0.046 & 0.072 \\
D.W. & 1.94 & 2.37 & 1.74 & 1.90 & 2.08 & 2.39 \\
$\sigma_{\text {pre-crash }}$ & 0.0001 & 0.003 & -0.004 & -0.006 & 0.01 & -0.009 \\
$\sigma_{\text {post-crash }}$ & 0.0006 & 0.002 & -0.002 & -0.004 & -0.008 & $-0.05^{* *}$ \\
\hline
\end{tabular}

a. Absolute value of $t$-ratios in parentheses.

*Significant at the $1 \%$ level.

**Significant at the $10 \%$ level.

in the period following the crash, we test for structural change in the regression equations. For this purpose, we include both intercept and slope dummy variables in each of the six equations and reestimate the model. ${ }^{17}$ The dummy variables take on the value of zero prior to the fourth quarter of 1987 and one thereafter. The results are in Table II.

The only dummy variable that has a significant parameter estimate at the $5 \%$ level is the intercept dummy in the housing equation where it has a negative sign. This suggests that since the crash there has been a downward shift in the demand for residential housing. Because the sum of the constant term and the intercept dummy, as well as the sum of the slope term and the slope dummy enter the Hicks-Allen substitution elasticities, we test for the significance of these sums in the post-crash period. In the housing equation, the former sum is significant at the $1 \%$ level, but the latter is not. This means that the calculated elasticity of substitution between stocks and housing cannot be different from zero in the post-crash period, same as it was in the pre-crash period. To sum up, we find no evidence suggesting that the crash exerted a significant effect on the substitutability of stocks and the other assets.

The test of structural change generates an interesting result. Recall that we found previously that over the entire sample period the only assets with a statistically significant parameter estimate, though only at the $10 \%$ level, were time deposits and Treasury bills. Now, with the dummy variables included in the model, we find that these two assets relate differently to common stocks. As far as time deposits are concerned, both before and after the crash the estimated coefficients of

17. We did not use the popular Chow test because there is not enough degrees of freedom in the period following the crash for estimating the model using a system approach. Moreover, using the dummy variable approach allows us to not only determine if there was a change due to the crash but also to calculate the desired elasticities in the post-crash period. 
relative yield and the slope dummy are individually and jointly insignificant. This means that the resulting elasticity of substitution between stocks and time deposits cannot be different from zero.

Turning to Treasury bills, we observe that while in the period prior to the crash the elasticity of substitution between equities and Treasury bills is statistically insignificant, in the period following the crash the slope coefficients on the relative yield and slope dummy are jointly significant at the $10 \%$ level (chi squared $=3.05$ ). The resulting elasticity is -0.05 , indicating that Treasury bills are actually considered complements to stocks in the period following the crash. Earlier (see Table I), we found that over the entire sample period the elasticity of substitution between stocks and Treasury bills was significant and negative. Now (see Table II), we find that in the pre-crash period this elasticity is insignificant but in the post-crash period it is significant and negative. It follows that the significant negative overall elasticity between stocks and T-bills is due to the post-crash complementarity between these two assets. This apparent complementarity can be explained by the events surrounding the October 1987 stock market crash.

Many investors viewed the stock market crash as a signal of an impending financial panic. This led many investors to move out of equities and into Treasury bills. This excess demand raised the price of Treasury bills, lowering their yield. Also, at this time, the Federal Reserve flooded the market with liquidity in an effort to stem the panic in the financial markets. This lowered the yield on Treasury bills further. Thus, as the return on stocks was declining, so was the return on Treasury bills, explaining, at least in part, the apparent complementarity between Treasury bills and stocks in the post-crash period.

\section{Summary and Concluding Remarks}

In this paper we examined the degree of substitutability of stocks on the one hand and several financial assets and a tangible asset on the other. A utility maximization approach was used to derive a set of estimable equations whose parameters were used to calculate the (constant) elasticity of substitution between these assets.

Using quarterly data from 1963.4 to 1991.3 , we found that there is virtually no substitutability between stocks and other financial assets. Nor did we find any evidence supporting the contention that stocks and housing are substitute assets. This contradicts Runkle's suggestion that as stock returns decline, consumers may move their wealth into such durable goods as housing. In fact, it appears that individuals consider equities to be a requirement in their portfolio and are not willing to use other assets as substitutes.

We also found that the stock market crash of 1987 did not have a significant impact on the substitutability between assets. In particular, we found no indication of substitutability between housing and stocks prior to or following the crash. Finally, we found that following the stock market crash, stocks and Treasury bills actually became complements, a result that we explained in terms of the events surrounding the stock market crash.

The analysis presented in this paper can be extended and improved in a number of ways. A natural extension of the modeling process would be to use a variable-elasticity of substitution (e.g., translog) functional form for the utility function. It would also be useful to examine the sensitivity of the results to alternative measures of the rate of return on housing. Also, in addition to the existing stock of residential housing, one could incorporate other durable goods. Another modification would be to use real estate investment trust holdings in place of the existing stock of housing as a measure of claims to real assets. One might also want to estimate a rate of return for $M I$ and savings and time deposits and incorporate them into the analysis. 


\section{References}

1. Aivazian, Varouj A., Jeffrey L. Callen, Izhak Krinsky, and Clarence C. V. Kwan, "An Empirical Portfolio Analysis of Financial Asset Substitutability: The Case of the U.S. Household Sector." Quarterly Review of Economics and Business, Summer 1986, 47-65.

2. Barnett, William A., "Economic Monetary Aggregates: An Application of Index Number and Aggregation Theory." Journal of Econometrics, Summer 1980, 11-48.

3. Brayton, Flint and Eileen Mauskopf, "Structure and Uses of the MPS Quarterly Econometric Model of the United States." Federal Reserve Bulletin, February 1987, 93-109. $270-81$.

4. Chetty, V. Karuppan, "On Measuring the Nearness of Near-Monies.” American Economic Review, June 1969,

5. Craine, Roger, "The Baby Boom, the Housing Market and the Stock Market." Federal Reserve Bank of San Francisco Economic Review, Spring 1983, 6-11.

6. Ewis, Nabil A. and Douglas Fisher, "Toward a Consistent Estimate of the Demand for Monies: An Application of the Fourier Flexible Form.” Journal of Macroeconomics, Spring 1985, 151-74.

7. Feige, Edgar L. The Demand for Liquid Assets: A Temporal Cross-Section Analysis. Englewood Cliffs, N.J.: Prentice-Hall, 1964.

8. — and Douglas K. Pearce, "The Substitutability of Money and Near-Monies: A Survey of the Time Series Evidence.” Journal of Economic Literature, June 1977, 439-69.

$\rightarrow-$ and P. A. V. B. Swamy, "A Random Coefficient Model of the Demand for Liquid Assets," Journal of Money, Credit and Banking, May 1974, 241-52.

10. Gauger, J. A. and John R. Schroeter, "Measuring the Nearness of Modern Near-Monies: Evidence from the 1980s.” Journal of Macroeconomics, Spring 1990, 247-61.

11. Garner, C. Alan, "Has The Stock Market Crash Reduced Consumer Spending?" Federal Reserve Bank of Kansas City Economic Review, April 1988, 3-16.

$\rightarrow$ Hamburger, Michael J., "The Demand for Money by Households, Money Substitutes, and Monetary Policy." Journal of Political Economy, December 1966, 600-23.

13. - "Household Demand for Financial Assets." Econometrica, January 1968, 97-118.

$\rightarrow$ Hicks, John R. and R. G. D. Allen, "A Reconsideration of the Theory of Value," Economica, May 1934, 196-219.

$\rightarrow$ Huang, Cliff J., Jen-Chi Cheng, Ching-Sheng Chou, and Shun-Ying Charles Lin, "The Substitutability of Monetary Assets in Taiwan." Southern Economic Journal, April 1992, 975-87.

16. Imoroghlou, Selahattin. "An Empirical Investigation Of Currency Substitution.” Working Paper no. 91-20, 1991, College of Business Administration, University of Southern California.

17. McGibany, James M., and Farrokh Nourzad, "The Substitutability of Real Capital and Financial Assets." Applied Economics, November 1988, 1445-51.

18. Miles, Marc A., "Currency Substitution, Flexible Exchange Rates, and Monetary Independence." American Economic Review, June 1978, 428-36.

$\rightarrow-$, "Currency Substitution: Some Further Results and Conclusions." Southern Economic Journal, July $1981,78-86$.

$\rightarrow$ Moroney, John R. and Barry J. Wilbratte, "Money and Money Substitutes: A Time Series Analysis of Household Portfolios." Journal of Money, Credit and Banking, May 1976, 181-98.

21. Poterba, James M. and Julio J. Rotemberg. "Money in the Utility Function: An Empirical Implementation," in New Approaches to Monetary Economics, edited by William A. Barnett and Kenneth J. Singleton. Cambridge: Cambridge University Press, 1987, pp. 219-40.

22. Runkle, David E., "Why No Crunch From the Crash?" Federal Reserve Bank of Minneapolis Quarterly Review, Winter 1988, 2-7.

23. Serletis, Apostolos. "Monetary Assets Separability Tests," in New Approaches to Monetary Economics, edited by William Barnett and Kenneth Singleton. Cambridge: Cambridge University Press, 1987, pp. 169-82.

$\rightarrow$ Swofford, James L. and Gerald A. Whitney, "Nonparametric Tests of Utility Maximization and Weak Separability for Consumption, Leisure and Money." Review of Economics and Statistics, August 1987, 458-64.

25. _ and , "A Comparison of Nonparametric Tests of Weak Separability for Annual and Quarterly Data on Consumption, Leisure, and Money.” Journal of Business and Economic Statistics, April 1988, 241-46. 